\title{
Stress-related hormone reduces autophagy through the regulation of phosphatidylethanolamine in breast cancer cells
}

\author{
Zhen Zhu ${ }^{1 \#}$, Ruihua Yu ${ }^{2 \#}$, Chao Yang ${ }^{2 \#}$, Dong Li ${ }^{2 \#}$, Jiawei Wang ${ }^{1}$, Wanli Yang ${ }^{2}$, Yonghua Ji ${ }^{1,2}$, Li Wang ${ }^{2}$, \\ Yaosheng Wang ${ }^{2}$, Feng Jiang ${ }^{2 \wedge}$ \\ ${ }^{1}$ School of Life Sciences, Shanghai University, Shanghai, China; ${ }^{2}$ Translational Institute for Cancer Pain, Clinical Research and Innovation Unit, \\ Xinhua Hospital Affiliated to Shanghai Jiao Tong University School of Medicine, Chongming Branch, Shanghai, China \\ Contributions: (I) Conception and design: F Jiang; (II) Administrative support: Y Ji, Y Wang, F Jiang; (III) Provision of study materials: Y Ji, D Li, \\ L Wang; (IV) Collection and assembly of data: Z Zhu, R Yu, C Yang, J Wang; (V) Data analysis and interpretation: Z Zhu, L Wang, W Yang; (VI) \\ Manuscript writing: All authors; (VII) Final approval of manuscript: All authors. \\ \#These authors contributed equally to this work. \\ Correspondence to: Feng Jiang, PhD; Yaosheng Wang, PhD; Li Wang, PhD. Translational Institute for Cancer Pain, Clinical Research and Innovation \\ Unit, Xinhua Hospital Affiliated to Shanghai Jiao Tong University School of Medicine, Chongming Branch, Shanghai, China. Email: fengjiang@ \\ xinhuamed.com.cn; wangyaosheng@xinhuamed.com.cn; lilymaq@163.com.
}

\begin{abstract}
Background: An increasing number of studies indicate that adrenergic signaling plays a fundamental role in tumor progression and metastasis induced by chronic stress. However, despite the growing attention, an understanding of the mechanisms linking chronic stress and cancer is still insufficient.

Methods: Western blot analysis and transmission electron microscopy (TEM) were used to observe the changes in autophagy level in a breast cancer cell line (MCF-7) after epinephrine treatment. Non-targeted metabolomics was also used to detect MCF-7 metabolites after epinephrine treatment. The xenograft model was used to detect the level of autophagy after epinephrine intervention.

Results: The results showed that epinephrine treatment reduced the autophagy level of breast cancer cells. Epinephrine changed the level of phosphatidylethanolamine (PE) in breast cancer cells as detected by nontargeted metabolomics. Epinephrine also changed autophagy in breast cancer cells by decreasing the level of $\mathrm{PE}$ in cells. When autophagy decreased, the invasion and migration of breast cancer cells increased in vitro, and the progression of breast cancer accelerated in vivo.

Conclusions: These findings suggest that stress-related hormones affect the tumor progression of breast cancer. Therefore, strengthening the emotional management strategies of patients during the process of antitumor treatment as a supplement to the existing treatments may be beneficial.
\end{abstract}

Keywords: Chronic stress; epinephrine; autophagy; breast cancer

Submitted Nov 16, 2020. Accepted for publication Jan 21, 2021.

doi: 10.21037/atm-20-8176

View this article at: http://dx.doi.org/10.21037/atm-20-8176

\section{Introduction}

Stress, whether physiological or biological, is the response of an organism to a stressor (such as environmental conditions) (1). Stress is how bodies adapt to a complicated environment through combat, escape, or physiological and psychological changes. Multiple systems in the body respond to stimuli and alterations in the environment. In humans and most mammals, the autonomic nervous system and the hypothalamic-pituitary-adrenal (HPA) axis are the two major systems that respond to stress (2). Chronic stress is the response to emotional pressure

^ ORCID: 000-0002-8071-8279. 
suffered for a prolonged period of time during which an individual perceives that they have little or no control. The sympathetic and parasympathetic nervous systems govern the functioning of most internal organs. These nerves play an important role in maintaining homeostasis by directly innervating tissues or secreting neurotransmitters such as epinephrine, norepinephrine, and acetylcholine (3). Several studies have shown that chronic stress affects the occurrence and development of some tumors by inducing the release of neurotransmitters (4-7), such as epinephrine, norepinephrine and glucocorticoid. On the other hand, life care and emotional management for cancer patients can effectively prolong patients' survival, and some animal model and human based studies have confirmed the link between stress reduction and cancer inhibition (8-12). The influence of chronic stress on tumor development has therefore become of increasing concern.

Breast cancer is the leading cause of cancer death in women worldwide (13). Despite some progress in diagnosis and treatment, a large number of women still die of metastatic breast cancer (14). Patients with breast cancer, especially those diagnosed with advanced breast cancer, rarely receive an optimistic prognosis. Therefore, a more detailed understanding of the molecular mechanisms of the growth and diffusion of breast cancer cells is needed to develop and improve treatment strategies for breast cancer.

In the past decade, metabolomics has emerged as a powerful tool to understand the metabolic changes, particularly in small molecules $(<1,000 \mathrm{Da})$, that occur in response to pathophysiological conditions (15). To detect changes in cellular metabolites, liquid chromatography in conjunction with mass spectrometry techniques can accurately and effectively detect a large number of isolated cellular metabolites (16). Analysis of changes in these metabolites can allow us to quickly determine the changes in the external environment that have affected the interior of the cell, and thus, more intuitively study and explain many physiological phenomena. In recent years, metabolomics has been widely applied to toxicology, organic acid disorders, and whole-body metabolic disorders (17). However, to the best of our knowledge, few studies have used this method to understand the internal changes in tumor cells in a particular physiological state.

In contrast to the process of programmed cell death (apoptosis), autophagy is a process of programmed cell survival (18). Cells degrade and reuse their organelles and components of proteins to meet their metabolic needs and to renew organelles. In 1999, a landmark discovery connecting autophagy with cancer was published by Beth Levine's group (19). Autophagy has been considered an accomplice of tumor cells, enabling them to attain an unlimited ability to replicate, though recent basic research has shown that autophagy decreases the occurrence of tumors (20). Autophagy may be involved in immortalization in maintaining cell survival, so autophagy plays distinct roles in different time points of tumor development. However, insufficient attention has been paid to the effects of neurotransmitters on tumors. In this study, the effect of adrenergic receptor activation on the internal production of metabolites in breast cancer was explored through in vitro culture of breast cancer cell lines, and metabolomics. After tumor cells were treated with drugs, metabolites were analyzed to determine their influence on tumor progression, as well as the in vivo regulation of microenvironmental homeostasis by tumor cells under different physiological conditions. We present the following article in accordance with the ARRIVE reporting checklist (available at http:// dx.doi.org/10.21037/atm-20-8176).

\section{Methods}

\section{Cell culture}

The human breast cancer cell line MCF-7 was purchased from the Cell Bank (Shanghai Institutes for Biological Sciences and Chinese Academy of Sciences). Cells were cultured in Dulbecco's Modified Eagle's Medium (DMEM, Gibco, 11965-092) supplemented with antibiotics and 10\% heat-inactivated fetal bovine serum (Gibco, 16000-044) at $37^{\circ} \mathrm{C}$ in a humidified atmosphere of $5 \% \mathrm{CO}_{2}$.

\section{Sample processing and analysis of ultra-performance liquid chromatography linked with mass spectrometry (LC- MS)}

Cells from each group were calculated accurately, and equal amounts were added to $400 \mu \mathrm{L}$ of prechilled methanol solution (methanol:water $=4: 1$ ) and disrupted using a lowtemperature, high-throughput tissue homogenizer. Samples were then vortexed and ultrasonically extracted on ice for $10 \mathrm{~min}$, and this process was repeated 3 times. The extracted sample was allowed to stand at $-20^{\circ} \mathrm{C}$ for $30 \mathrm{~min}$ and then centrifuged $(13,000 \mathrm{~g})$ for $15 \mathrm{~min}$ at $4{ }^{\circ} \mathrm{C}$. The supernatant was transferred to the container for testing. LC-MS was performed, and the system of the analysis platform was UPLC-TripleTOF (Co., AB SCIEX). A 
BEH C18 column $(100 \mathrm{~mm} \times 2.1 \mathrm{~mm}$ i.d., $1.7 \mu \mathrm{m}$; Waters, Milford, USA) was used. Mobile phase A was water $(0.1 \%$ methanoic acid), while mobile phase B was acetonitrile and isopropanol (acetonitrile:isopropanol =1:1). The mobile phase flow rate was set at $0.40 \mathrm{ml} / \mathrm{min}$, and the injection volume was $20 \mu \mathrm{L}$ at $40{ }^{\circ} \mathrm{C}$. Mass spectrum signals were collected from samples in positive and negative scan modes. The electrospray capillary voltage, injection voltage, and collision energy were $1.0 \mathrm{kV}, 40 \mathrm{~V}$, and $6 \mathrm{eV}$, respectively. The ion source temperature and desolvation temperatures were 120 and $500{ }^{\circ} \mathrm{C}$, respectively. The carrier gas flow rate was $900 \mathrm{~L} / \mathrm{h}$, the mass scan range was $50-1,000 \mathrm{~m} / \mathrm{z}$, and the resolution was 30,000 .

\section{Cell migration assay}

MCF-7 cells were seeded at a density of $2 \times 10^{4}$ cells per well into a 6 -well plate. Cells were pretreated with or without propranolol for $45 \mathrm{~min}$, and then with or without epinephrine. After $24 \mathrm{~h}$, the cells were washed with PBS 3 times. Cells in the denuded zone of 10 random fields were quantified using an inverted fluorescence microscope. The migration indices were calculated as follows: [ $\mathrm{At}=0 \mathrm{~h}-$ $A t=\Delta h) / A t=0 h] \times 100 \%$, where "At=0 h" is the area of the wound measured immediately after scratching, and "At $=\Delta \mathrm{h}$ " is the area of the wound at the time point $24 \mathrm{~h}$ after scratching.

\section{Cell invasion assay}

MCF-7 cells $\left(3 \times 10^{3}\right)$ in $200 \mu \mathrm{L}$ DMEM without fetal bovine serum were placed in the upper chamber of a transwell insert (24 wells, $8 \mu \mathrm{m}$ pore size; Corning Costar) coated with Matrigel (Corning, 356237). The lower chambers were loaded with $10 \mu \mathrm{M}$ epinephrine (Sigma, E4642) or $20 \mu \mathrm{M}$ propranolol (Sigma, P0884) in $500 \mu \mathrm{L}$ DMEM with $10 \%$ fetal bovine serum or culture medium only as a control. After incubation at $37^{\circ} \mathrm{C}$ for $24 \mathrm{~h}$, cells were removed from the upper chamber using a cotton swab, and the cells on the lower membrane surface were fixed with $4 \%$ formalin, stained with $0.1 \%$ crystal violet for visualization, and counted under a microscope (Leica).

\section{Protein extraction and western blot}

Total protein was collected from $5 \times 10^{8}$ MCF-7 cells by lysis in $200 \mu \mathrm{L}$ of ice-cold RIPA buffer with PMSF. The extracted protein concentration was determined using the
BCA Protein Assay (Beyotime, P0009). Approximately $30 \mu \mathrm{g}$ protein was loaded into each well of a polyacrylamideSDS gel. After electrophoresis, proteins were transferred onto PVDF membranes (Thermo Fisher). The membranes were initially blocked with $5 \%$ non-fat dry milk in trisbuffered saline for $1 \mathrm{~h}$ at room temperature, and then incubated with the primary antibody overnight at $4{ }^{\circ} \mathrm{C}$. This was followed by incubation with the secondary antibody for $2 \mathrm{~h}$. Immunoreactive bands were detected with Trident ECL (Beyotime, P0018FM).

\section{Xenograft tumor model}

The xenograft model experiment was performed with nude mice (14-16 g) purchased from Sino-British SIPPR/ BK Lab Animal Co. Mice were housed at 5 mice per cage and maintained on a $12 \mathrm{~h}$ light:12 h dark cycle (lights on at 8.00 a.m.) at $22 \pm 2{ }^{\circ} \mathrm{C}$, and were provided with food and water ad libitum. All animal procedures complied with a protocol approved by the ethics committee of the Xinhua Hospital affiliated to Shanghai Jiao Tong University School of Medicine, Chongming Branch (No. LLWYH-2016-13). All procedures were performed following the Guide for the Care and Use of Laboratory Animals and complied with institutional ethical guidelines.

After 1 week of acclimation to the housing conditions, mice were injected subcutaneously with $1 \times 10^{7} \mathrm{MCF}-7$ cells suspended in $0.2 \mathrm{~mL}$ of PBS. Prior to implantation, we confirmed that the tumor cells were negative for the presence of mycoplasma and mouse pathogens. The drug was administered when the tumor grew to $300 \mathrm{~mm}^{3}$, and mice were treated with epinephrine (E) $10 \mathrm{mg} / \mathrm{kg}$ and propranolol (Pro) $2 \mathrm{mg} / \mathrm{kg}$ respectively or both. All treatments were administered by intraperitoneal injection in a total volume of $100 \mu \mathrm{l}$ every other day for 10 days. Tumor growth was measured twice a week with a digital caliper 2BIOL (Besozzo). Xenograft volumes were calculated using the following formula: volume $=\left(a \times b^{2}\right) / 2$, where $a$ is the largest superficial diameter, and $\mathrm{b}$ is the smallest superficial diameter.

\section{Transmission electron microscopy}

MCF-7 cells and tumor samples were isolated at a size of no $>1 \mathrm{~mm}^{3}$ and fixed with $2.5 \%$ glutaraldehyde at $4{ }^{\circ} \mathrm{C}$ for $4 \mathrm{~h}$. Post-fixation, the samples were dehydrated with a graded series of ethanol $(30 \%, 50 \%, 70 \%, 80 \%, 90 \%, 95 \%$ and $100 \%$ ) and propylene oxide and then were embedded in an 
epoxy resin. The embedded samples were then processed for transmission electron microscopy following standard procedures. Finally, the ultrathin sections were examined with an HT7700 electron microscope (HITACHI).

\section{Statistical analysis}

The collected data were analyzed using IBM SPSS Statistics 22. Data are presented as the mean \pm standard deviation (SD). Two groups were compared using the Student's $t$-test. $\mathrm{P}<0.05$ was considered significant $\left({ }^{*} \mathrm{P}<0.05\right.$, $\left.{ }^{* * *} \mathrm{P}<0.001\right)$. All experiments were repeated at least 3 times, and representative data are shown.

\section{Results}

\section{PE level is decreased by epinephrine treatment}

Previous research has reported that epinephrine alters the cell cycle and the occurrence of apoptosis in breast cancer cells (21). In this study, to further explore the effect of epinephrine on MCF-7 cells, we examined the changes in the total metabolites of MCF-7 cells after epinephrine treatment. The results of each group of samples were highly stable (Figure 1A,B), and the species (Figure 1C) of 961 changed metabolites (Figure 1D) were classified according to the Human Metabolome Database (HMDB 4.0) database. In addition, we found that PE level in MCF7 cells after epinephrine treatment decreased significantly (Figure 1E). PE plays a key role in lysosomal maturation in cell autophagy, which mainly involves the localization between autophagosomes and lysosomes.

\section{Effect of epinephrine on the level of autophagy in MCF-7 cells}

We examined autophagy-related indicators in MCF7 cells in vitro following epinephrine treatment. The results showed that epinephrine significantly increased the expression of p62 and decreased the ratio of LC3 II/I in MCF-7 cells (Figure 2A,B). The results of transmission electron microscopy (TEM) (Figure 2C) showed that epinephrine significantly increased the number of autophagosomes (Figure 2D) and decreased the number of autolysosomes (Figure 2E) in breast cancer cells, confirming that epinephrine significantly altered the level of autophagy in MCF-7 cells under our experimental conditions.

\section{$P E$ regulates the level of autophagy in MCF-7 cells in a dose-dependent manner}

The method of Rockenfeller et al. was used as a reference for this experiment (22). The PE pool in the cells was improved by adding ethanolamine. The change of $\mathrm{PE}$ in MCF-7 cells resulted in a change in the autophagy level, and changes in autophagosomes were observed by TEM (Figure 3A,B,C). Moreover, western blot analysis showed that the increase in PE concentration led to a significant increase in the ratio of LC3 II/I (Figure 3D) and a significant decrease in p62 (Figure 3E) in MCF-7 cells. Epinephrine treatment significantly reversed these changes. In terms of MCF-7 cell activity, the increase in PE concentration significantly inhibited cell migration (Figure $3 F, G$ ) and invasion (Figure $3 \mathrm{H}, \mathrm{I}$ ), which could also be rescued by epinephrine.

\section{Epinephrine affects the malignancy of breast cancer, partly through autophagy}

To determine whether the increase in epinephrine affected the malignancy of breast cancer by changing the level of $\mathrm{PE}$ in tumor cells, we verified the above findings in vivo. Following epinephrine treatment, the autophagy level of MCF-7 xenograft tumors increased significantly (Figure $4 A, B, C$ ), and propranolol rescued the changes in the LC3 II/I ratio and p62 induced by epinephrine (Figure 4D,E). Moreover, epinephrine affected the level of tumor malignancy and promoted tumor progression, and propranolol also rescued this phenomenon (Figure 4F,G,H). These results indicate that epinephrine changes $\mathrm{PE}$ level in MCF-7 cells, which leads to changes in autophagy level.

\section{Discussion}

Neurotransmitters, hormones, and signaling molecules have been shown to bridge the gap between nerves and tumors, and affect the growth and malignancy of tumor cells. For example, sympathetic and parasympathetic nerves can infiltrate the tumor microenvironment and actively stimulate the progression of cancer (23-26). In recent years, as medical treatments have progressed, the psychological health and quality of life of cancer patients during the treatment process have been widely discussed (27). Chronic stress affects the function of the nervous, immune, and endocrine systems. Moreover, some studies have shown that tumor innervation is a part of the tumor microenvironment, 
A

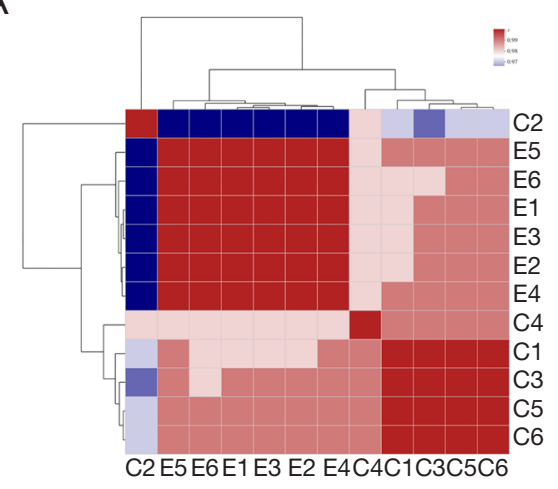

C

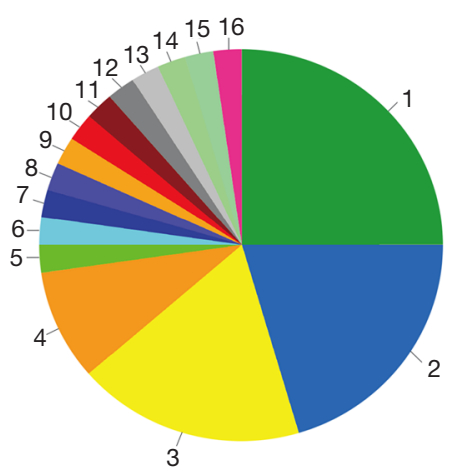

$E$

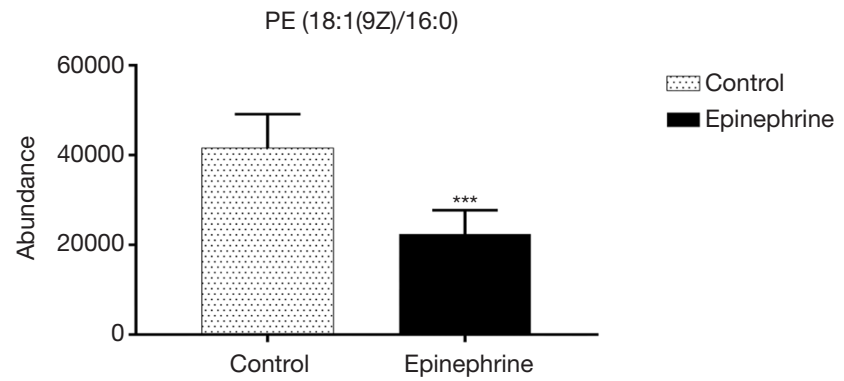

$E$
B

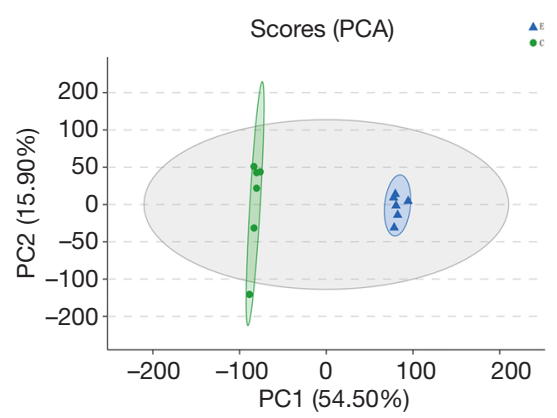

D

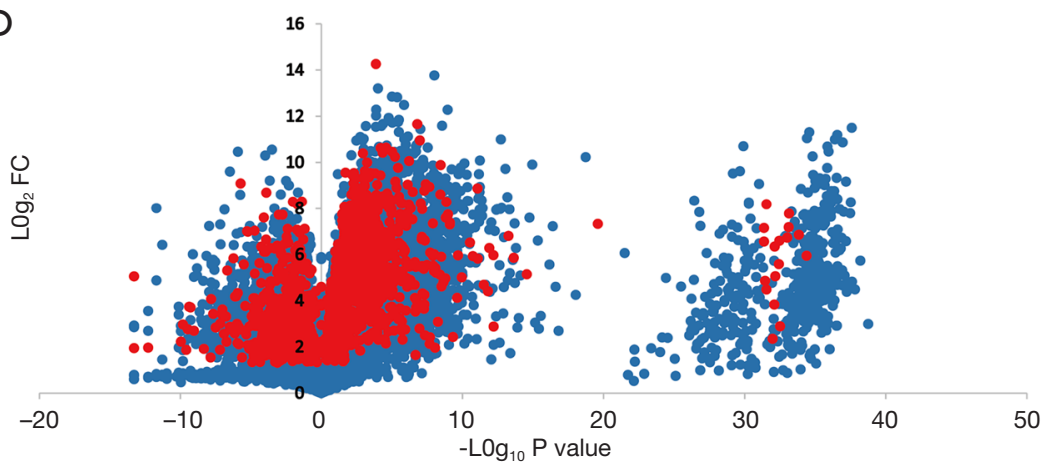


A

B
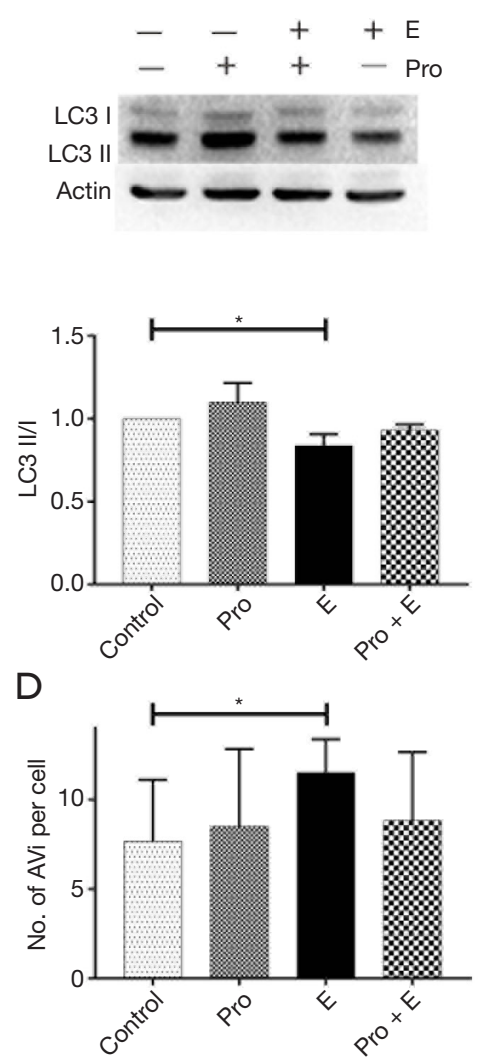
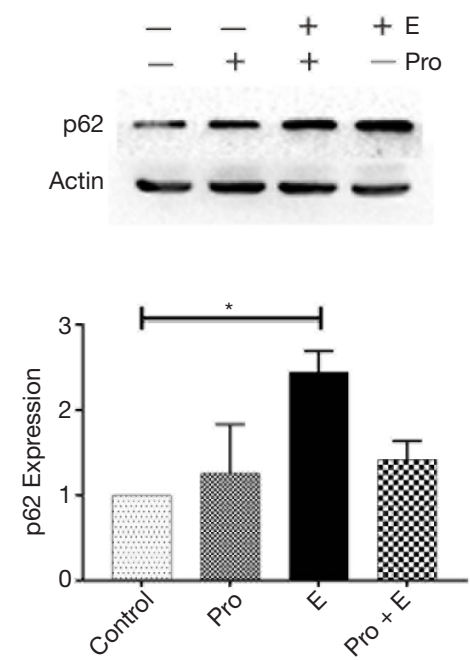

E

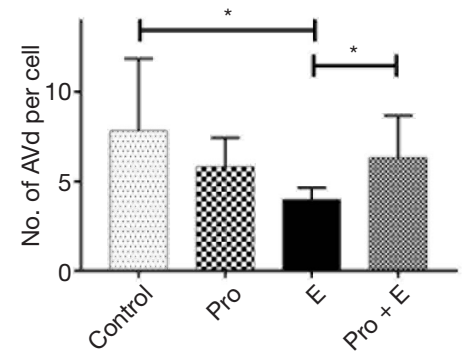

C
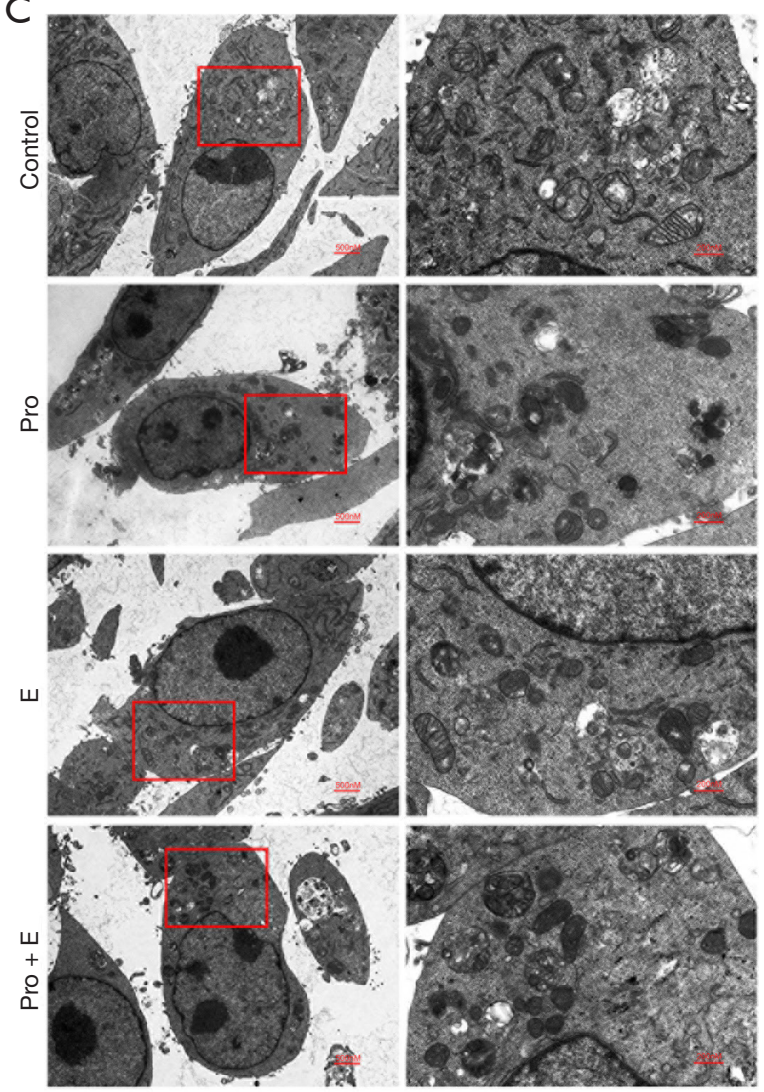

Figure 2 Epinephrine reduces autophagy in breast cancer. The protein expression of LC3 (A) and p62 (B) in a breast cancer cell line (MCF-7) treated with or without epinephrine (E, $10 \mathrm{mM}$ ) and propranolol (Pro, $20 \mathrm{mM}$ ) for 24 h was measured by western blot. (C) Representative transmission electron microscopy (TEM) images depicting the ultrastructures of cells in the different groups. The cells were stained with uranium acetate and lead citrate. An autophagosome (initial autophagic vacuoles, AVi) is a spherical structure with a double layer membrane, delivering cytoplasmic components to lysosomes after formation. Autophagosomes bind to lysosomes to form a monolayer structure of autolysosomes (degrading autophagic vacuoles, AVd), and the hydrolase degrades its contents and intima. AVi (D) and AVd (E) were calculated per cell, and 6 cells were analyzed per treatment condition. ${ }^{*} \mathrm{P}<0.05$.

and the regulation of the nervous system affects the development of tumor cells $(28,29)$. For example, in clinical antitumor treatment, doctors often use surgery to destroy the nerve plexus near the tumor to relieve cancer pain and tumor progression $(30,31)$. Following the diagnosis of a malignant tumor, fears of cancer and the side effects of antitumor treatment lead to suffering and chronic stress in cancer patients (32). It is now well-established that psychological stress is associated with detrimental effects on physical health, and cancer is also affected by stress. Some literatures show that women with negative emotions are more likely to suffer from cancer $(33,34)$, so there may be a vicious circle between chronic stress and cancer occurrence and development.

In addition, cellular autophagy has been shown to be related to anti-immortalization. Nassour and his team reported that autophagy is one of the key checkpoints of normal cell carcinogenesis, which is also related to the progression of tumor cells and may be affected by signal transduction (20). Under our experimental conditions, the concentration of $\mathrm{PE}$ in cells decreased significantly after the activation of the adrenergic receptor, which further affected cell mobility and malignancy by changing autophagy level. Epinephrine may potentially mediate tumor progression by directly affecting the process of LC3 modification in breast cancer patients experiencing chronic stress. In 
A

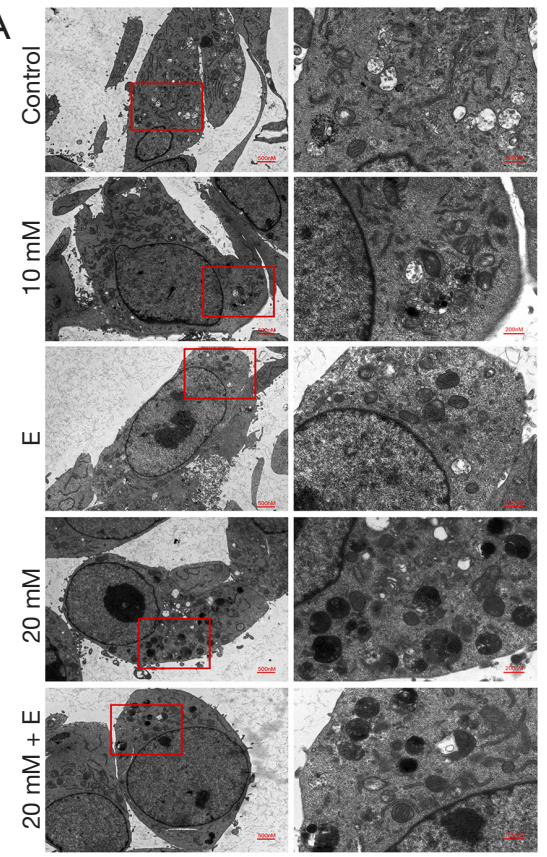

$\mathrm{F}$

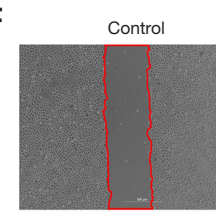

$\mathrm{H}$

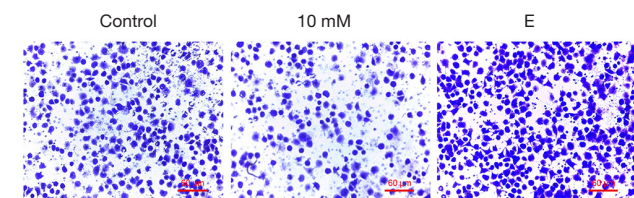

E
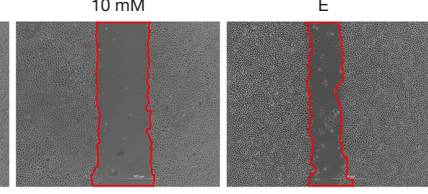

B
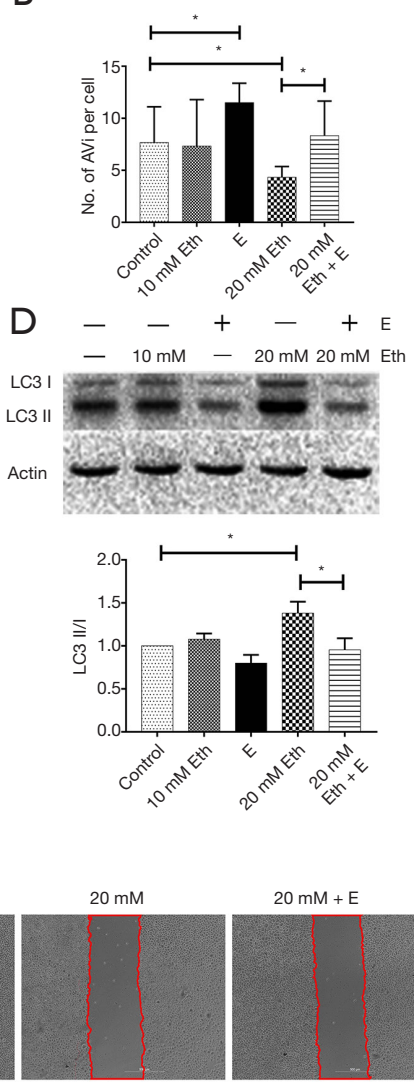

$20 \mathrm{mM}$

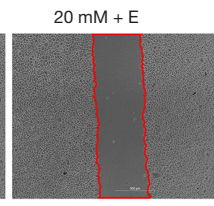

$20 \mathrm{mM}+\mathrm{E}$

C

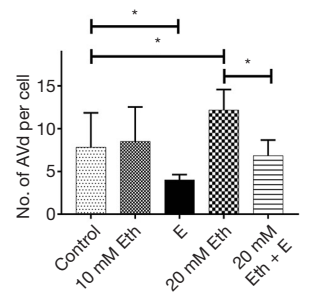

$\mathrm{E}$
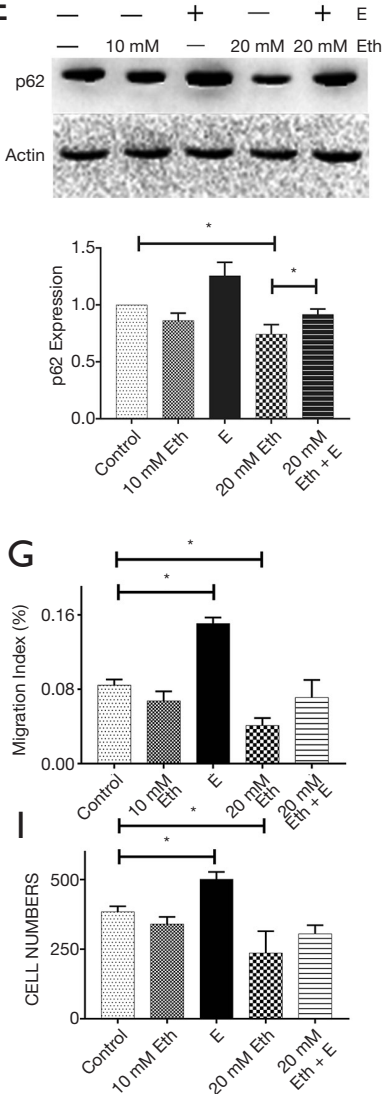

Figure 3 Phosphatidylethanolamine (PE) regulates the level of autophagy in MCF-7 cells. (A) Representative transmission electron microscopy (TEM) images depicting the ultrastructures of cells in the different groups. The cells were stained with uranium acetate and lead citrate. AVi (B) and AVd (C) were calculated per cell, and 6 cells were analyzed per treatment condition. The protein expression of LC3 (D) and p62 (E) in a breast cancer cell line (MCF-7) treated with or without epinephrine (E, $10 \mathrm{mM}$ ) and ethanolamine (Eth, 10 or $20 \mathrm{mM}$ ) for $24 \mathrm{~h}$ was measured by western blot. $(\mathrm{F})$ The migration ability was measured $(\mathrm{G})$ by wound-healing assay. $(\mathrm{H})$ The cells were stained with crystal violet and invasive ability was measured (I) by Transwell assay. ${ }^{*} \mathrm{P}<0.05$.

breast cancer autophagy, PE participated in the key step of the localization of autophagosomes to lysosomes, which is necessary for LC3 lipidation. Because the downstream effect of adrenergic receptor signaling on the rate-limiting enzyme in PE synthesis and the synthetic cycle of PE in normal cells (35) is still unclear, the current results have some limitations. Our study referred to some clinical statistics, including the effect of $\beta$-blockers on tumor progression $(36,37)$. Although related drugs have not yet been used directly to treat breast cancer, some preclinical studies in other tumor types validate the possibility of $\beta$-blockers as adjuvant anticancer therapy $(38,39)$. Indeed, 
A
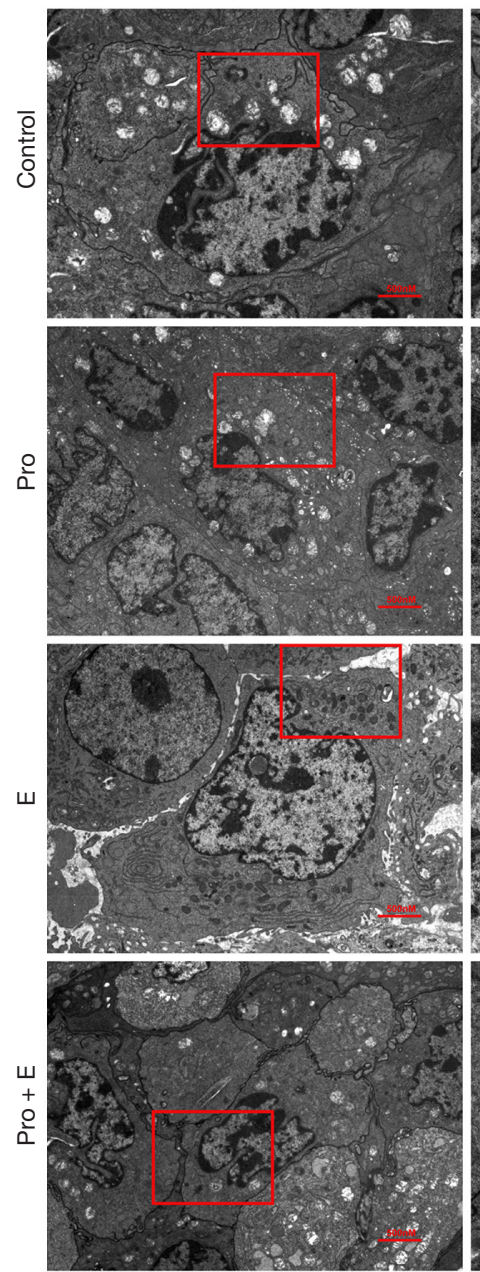

B

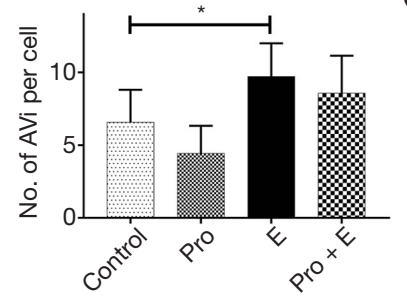

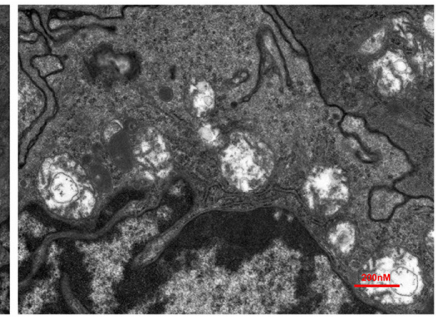
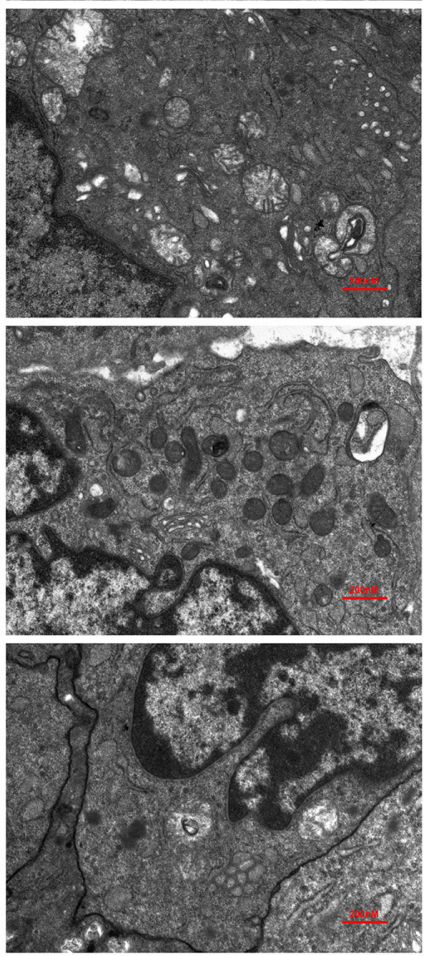

C

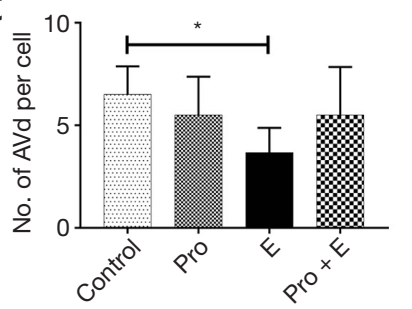

D
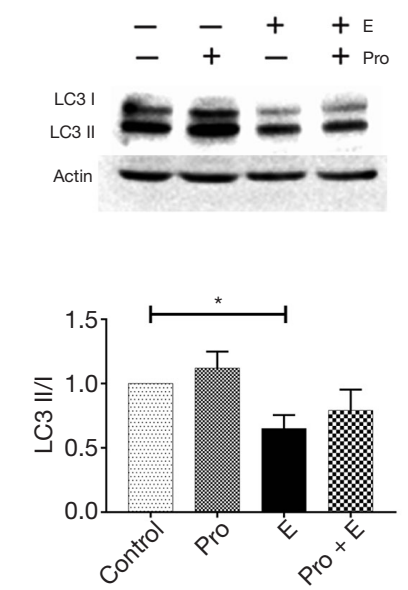

$\mathrm{E}$
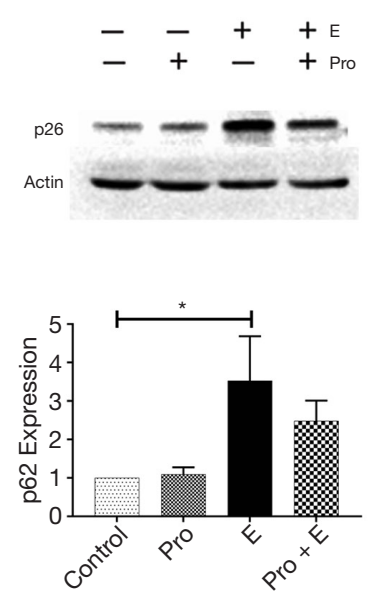
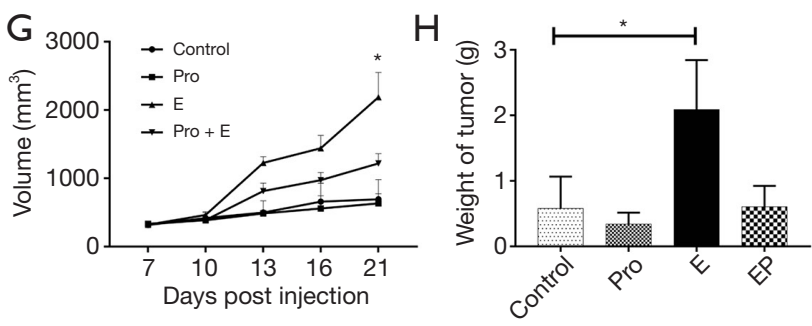

Figure 4 Epinephrine affects the malignancy of breast cancer partly through autophagy. (A) Representative transmission electron microscopy (TEM) images depicting the ultrastructures of cells in the different groups. Tissues was stained with uranium acetate and lead citrate. AVi (B) and AVd (C) were calculated for every tumor. The protein expression of LC3 (D) and p62 (E) in groups of tumors treated with or without epinephrine (E, $10 \mathrm{mg} / \mathrm{kg}$ ) and propranolol (Pro, $2 \mathrm{mg} / \mathrm{kg}$ ) for $24 \mathrm{~h}$ was measured by western blot. (F) Nude mouse xenograft model tumors between groups, including their volume $(\mathrm{G})$ and weight $(\mathrm{H}) .{ }^{*} \mathrm{P}<0.05$. 
the current data only reflect the role of $\beta$-receptors. More experiments specifically targeting $\alpha$-receptors should be designed and validated in the future to confirm whether the $\alpha$-receptors play roles in this process.

Taken together, our data showed that activation of the adrenergic receptor decreased the concentration of $\mathrm{PE}$ and affected autophagy in breast cancer cells, and promoted the invasion and migration of breast cancer cells. These data contribute towards a better understanding of the impact of chronic stress on the progression of breast cancer, and indicate that adrenergic receptor blockers may be effective for controlling the progression of breast cancer and improving the prognosis of patients.

\section{Acknowledgments}

Funding: This research was supported by Shanghai Health Committee (201840003, 20184Y0016, 201640201) and partly funded by Chongming Science and Technology Committee (CKY2019-06), Xinhua Hospital Chongming Branch Scientific Program (2019YA06, 2019YA12) and New Medicine Postgraduate Innovation Program of Shanghai University.

\section{Footnote}

Reporting Checklist: The authors have completed the ARRIVE reporting checklist. Available at http://dx.doi. org/10.21037/atm-20-8176

Data Sharing Statement: Available at http://dx.doi. org/10.21037/atm-20-8176

Conflicts of Interest: All authors have completed the ICMJE uniform disclosure form (available at http://dx.doi. org/10.21037/atm-20-8176). Dr. FJ and Dr. LW reports grants from Shanghai Health Committee, during the conduct of the study; Dr. JW reports grants from New Medicine Postgraduate Innovation Program of Shanghai University, during the conduct of the study; Dr. CY reports grants from Shanghai Health Committee, grants from Chongming Science and Technology Committee, grants from Xinhua Hospital Chongming Branch Scientific Program, during the conduct of the study; Dr. RY reports grants from Xinhua Hospital Chongming Branch Scientific Program, during the conduct of the study. The other authors have no conflicts of interest to declare.
Ethical Statement: The authors are accountable for all aspects of the work in ensuring that questions related to the accuracy or integrity of any part of the work are appropriately investigated and resolved. This study was approved by the ethics committee of the Xinhua Hospital affiliated to Shanghai Jiao Tong University School of Medicine, Chongming Branch (No. LLWYH-2016-13). All procedures were performed following the Guide for the Care and Use of Laboratory Animals and complied with institutional ethical guidelines.

Open Access Statement: This is an Open Access article distributed in accordance with the Creative Commons Attribution-NonCommercial-NoDerivs 4.0 International License (CC BY-NC-ND 4.0), which permits the noncommercial replication and distribution of the article with the strict proviso that no changes or edits are made and the original work is properly cited (including links to both the formal publication through the relevant DOI and the license). See: https://creativecommons.org/licenses/by-nc-nd/4.0/.

\section{References}

1. Del Giudice M, Buck CL, Chaby LE, et al. What is stress? A systems perspective. Integr Comp Biol 2018;58:1019-32.

2. Smith SM, Vale WW. The role of the hypothalamicpituitary-adrenal axis in neuroendocrine responses to stress. Dialogues Clin Neurosci 2006;8:383-95.

3. Zahalka AH, Frenette PS. Nerves in cancer. Nat Rev Cancer 2020;20:143-57.

4. Chen H, Liu D, Guo L, et al. Chronic psychological stress promotes lung metastatic colonization of circulating breast cancer cells by decorating a pre-metastatic niche through activating $\beta$-adrenergic signaling. J Pathol 2018;244:49-60.

5. Le CP, Nowell CJ, Kim FC, et al. Chronic stress in mice remodels lymph vasculature to promote tumour cell dissemination. Nat Commun 2016;7:10634.

6. Schmidt D, Peterlik D, Reber SO, et al. Induction of Suppressor Cells and Increased Tumor Growth following Chronic Psychosocial Stress in Male Mice. PLoS One 2016;11:e0159059.

7. Akbari ME, Kashani FL, Ahangari G, et al. The effects of spiritual intervention and changes in dopamine receptor gene expression in breast cancer patients. Breast Cancer 2016;23:893-900.

8. Li G, Gan Y, Fan Y, et al. Enriched environment inhibits mouse pancreatic cancer growth and down-regulates the expression of mitochondria-related genes in cancer cells. 
Sci Rep 2015;5:7856.

9. Cao L, Liu X, Lin ED, et al. Environmental and genetic activation of a brain-adipocyte BDNF/leptin axis causes cancer remission and inhibition. Cell 2010;142:52-64.

10. Ripoll RM, Casado IQ. Laughter and positive therapies: modern approach and practical use in medicine. Rev Psiquiatr Salud Ment 2010;3:27-34.

11. Laube R, Sabih AH, Strasser SI, et al. Palliative care in hepatocellular carcinoma. J Gastroenterol Hepatol 2020. [Epub ahead of print].

12. Irwin KE, Greer JA, Khatib J, et al. Early palliative care and metastatic non-small cell lung cancer: potential mechanisms of prolonged survival. Chron Respir Dis 2013;10:35-47.

13. DeSantis CE, Ma J, Gaudet MM, et al. Breast cancer statistics, 2019. CA Cancer J Clin 2019;69:438-51.

14. Lim B, Hortobagyi GN. Current challenges of metastatic breast cancer. Cancer Metastasis Rev 2016;35:495-514.

15. Fiehn O. Metabolomics--the link between genotypes and phenotypes. Plant Mol Biol 2002;48:155-71.

16. Domenick TM, Gill EL, Vedam-Mai V, et al. Mass Spectrometry-Based Cellular Metabolomics: Current Approaches, Applications, and Future Directions. Anal Chem 2021;93:546-66.

17. Bonvallot N, Tremblay FM, Chevrier C, et al. Potential input from metabolomics for exploring and understanding the links between environment and health. J Toxicol Environ Health B Crit Rev 2014;17:21-44.

18. Doherty J, Baehrecke EH. Life, death and autophagy. Nat Cell Biol 2018;20:1110-7.

19. Liang XH, Jackson S, Seaman M, et al. Induction of autophagy and inhibition of tumorigenesis by beclin 1 . Nature 1999;402:672-6.

20. Nassour J, Radford R, Correia A, et al. Autophagic cell death restricts chromosomal instability during replicative crisis. Nature 2019;565:659-63.

21. Ouyang X, Zhu Z, Yang C, et al. Epinephrine increases malignancy of breast cancer through p38 MAPK signaling pathway in depressive disorders. Int J Clin Exp Pathol 2019;12:1932.

22. Rockenfeller P, Koska M, Pietrocola F, et al. Phosphatidylethanolamine positively regulates autophagy and longevity. Cell Death Differ 2015;22:499-508.

23. Faulkner S, Jobling P, March B, et al. Tumor neurobiology and the war of nerves in Cancer. Cancer Discov 2019;9:702-10.
24. Boilly B, Faulkner S, Jobling P, et al. Nerve dependence: from regeneration to cancer. Cancer Cell 2017;31:342-54.

25. Griffin N, Faulkner S, Jobling P, et al. Targeting neurotrophin signaling in cancer: the renaissance. Pharmacol Res 2018;135:12-7.

26. Yang C, Sun Y, Ouyang X, et al. Pain May Promote Tumor Progression via Substance P-dependent Modulation of Toll Like Receptor-4. Pain Med 2020:Sep 11:pnaa265.

27. Ouyang XY, Yang C, Zhu Z, et al. Cancer pain, a serious threat to patientsmemory. Sheng Li Xue Bao 2019;71:343-9.

28. Li X, Dun MD, Faulkner S, et al. Neuroproteins in cancer: assumed bystanders become culprits. Proteomics 2018;18:e1800049.

29. Kuol N, Stojanovska L, Apostolopoulos V, et al. Role of the nervous system in cancer metastasis. J Exp Clin Cancer Res 2018;37:5.

30. Fontaine $\mathrm{D}$, Blond $\mathrm{S}$, Mertens $\mathrm{P}$, et al. Neurosurgical treatment of chronic pain. Neurochirurgie 2015;61:22-9.

31. Sidy K, Diouf D, Niang R, et al. Role of specific cancer treatments in pain management. Journal Integr Oncol 2017;6:186.

32. Law E, Girgis A, Sylvie L, et al. Telomeres and stress: Promising avenues for research in psycho-oncology. Asia Pac J Oncol Nurs 2016;3:137.

33. Chen YH, Lin HC. Increased risk of cancer subsequent to severe depression - a nationwide population-based study. J Affect Disord 2011;131:200-6.

34. Wang YH, Li JQ, Shi JF, et al. Depression and anxiety in relation to cancer incidence and mortality: a systematic review and meta-analysis of cohort studies. Mol Psychiatry 2020;25:1487-99.

35. Calzada E, Onguka O, Claypool SM. Phosphatidylethanolamine Metabolism in Health and Disease. Int Rev Cell Mol Biol 2016;321:29-88.

36. Barron TI, Connolly RM, Sharp L, et al. Beta blockers and breast cancer mortality: a population- based study. J Clin Oncol 2011;29:2635-44.

37. Melhem BA, Chavez MM, Lei X, et al. Beta-blocker use is associated with improved relapse-free survival in patients with triple-negative breast cancer. J Clin Oncol 2011;29:2645-52.

38. Chang CH, Lee CH, Ko JC, et al. Effect of $\beta$-Blocker in Treatment-Naïve Patients With Advanced Lung Adenocarcinoma Receiving First-Generation EGFRTKIs. Front Oncol 2020;10:583529. 
39. Nilsson MB, Sun H, Diao L, et al. Stress hormones promote EGFR inhibitor resistance in NSCLC: Implications for combinations with $\beta$-blockers. Sci Transl
Med 2017;9:eaao4307.

(English Language Editor: C. Betlazar-Maseh)

Cite this article as: Zhu Z, Yu R, Yang C, Li D, Wang J, Yang W, Ji Y, Wang L, Wang Y, Jiang F. Stress-related hormone reduces autophagy through the regulation of phosphatidylethanolamine in breast cancer cells. Ann Transl Med 2021;9(2):149. doi: 10.21037/atm-20-8176 